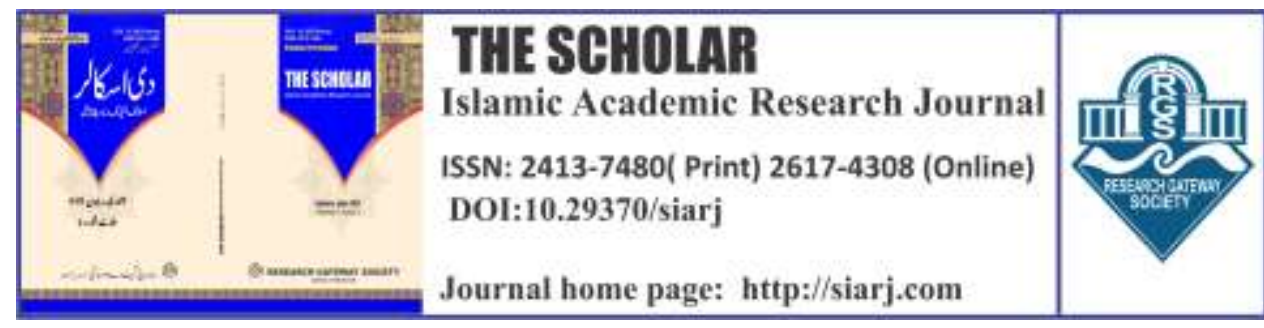

$$
\text { ثنائيات القرآن دراسة سورة الرحمن دلالية بلاغية }
$$

\title{
BINARIES SYNTAX IN SURAH AL RAHMAN
}

\author{
Lubna Farah \\ Languages (NUML), Islamabad Pakistan \\ Email: \\ lfarah@numl.edu.pk \\ ORCID ID:

\section{https://orcid.org/0000/0001-9977-1670}

Assistant Professor, Department of Arabic Language National University of Modern

To cite this article:

Farah, Lubna. "BINARIES SYNTAX IN SURAH AL RAHMAN." The ScholarIslamic Academic Research Journal 7, No. 2 (December 26, 2021).

To link to this article: https://doi.org/10.29370/siarj/issue13arabic2

\begin{tabular}{ll} 
Journal & $\begin{array}{l}\text { The Scholar Islamic Academic Research Journal } \\
\text { Vol. 7, No. 2 || July -December 2021|| P. 29-46 } \\
\text { Research Gateway Society }\end{array}$ \\
Publisher & 10.29370/siarj/issue13arabic2 \\
DOI: & https://doi.org/10.29370/siarj/ issue13arabic2 \\
URL: & Copyright c 2017 NC-SA 4.0 \\
License: & $\underline{\text { www.siarj.com }}$ \\
\hline Journal homepage & $2021-12-26$
\end{tabular}

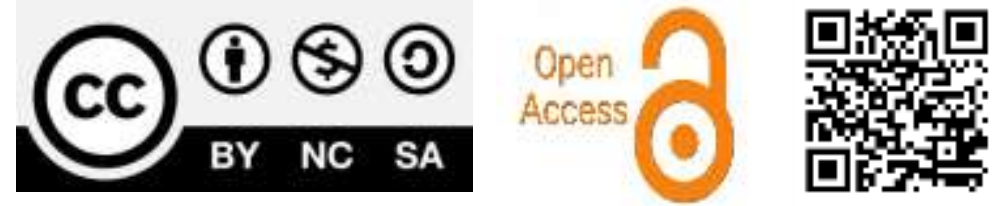


THE SCHOLAR (July-December 2021)

\section{ثنائيات القرآن دراسة سورة الرحمن دلالية بلاغية}

BINARIES SYNTAX IN SURAH AL RAHMAN

Lubna Farah

\section{ABSTRACT}

This paper study aims to analyze binaries words phenomena in Arabic with specific focus on Quran e.g "sura Rehman" the Binarity is the pattern of creation, existence the relation between the creator and pairs words, its event of Rhetoric of Quran, dark and light, night and day, life and hereafter. The conflict between man and devil and fall of Adam from heaven the conflict between Adam sons, the study is epistemological model based on the binary reality that leads to monotheistic perspective. The study ponders on Quran and investigates its consolidated epistemology and methodology. The epistemology model is grounded on binary reality which leads to a universal monotheistic perspective. The research paper discusses the central binaries in the Quran and analysis the most important methodological characteristics, such as structural, integration, overlapping, and aesthetic juxtaposition. The research design of this paper is descriptive qualitative, the results of the study shows that binaries has semantic aspect are of great value in understanding the Quranic texts, a trait that only Quranic texts contain.

KEYWORDS: Rhetoric, integration, Structural Unity, Binary, Surah Al Rahman.

$$
\text { الكلمات المفتاحية: البلاغة ، سورة الرحمن ، الوحلدة البنيوية ، ثنائية. }
$$




\section{الملخص:}

البحث يسعى لتوضيح مبدأ "الثنائية" وهي حقيقة اتفق العلم والدين والفلسفة عليها، وهي مظهر من مظاهر صنع الله كثير من الثنائيات تعلد اعملة اساسية في الثقافة الإسلاية، والثنائيات الفنية التي تأي على نمطين منها ثنائيات ضدية ومنها تكاملية وترتبط بقضايا وموضوعات مركزية، يعالجها التصور القرآي وهي أعمدة أساسية في الثقافة الإسلامية، ومثال على ذلك: الدنيا والآخرة، الفجور والثقوى، الصلاح والفساد، الجنة والنار، الحياة والموت، النور والظلام، التوحيد والشرك....الخح، الثنائيات تنقسم حسب طبيعتها وخصائصها لأقسام عدة، فمنها الثنائيات الوجودية. الثنائيات الأنفسية، الثنائيات السننية القيمة حيث الوجودية التي تتعلق ب"الخالق والخلوق، الإنسان والطبيعة" ام الأنفسية "اليسر العسر، الضحك والبكاء، التعب والراحة، الغني والفقر" القيمية التي لها صلة بالأخلاق والعلاقات الإنسانية، الآفاقية مالها صلة ب"السماء والأرض، الليل والنهار، الصيف والثتاء". الثنائيات تبدو واضحة إذا نظرنا إليها بأها حالة علية.

أهداف الدراسة تتضمن في التعرف على بنية نسقية تضم أصولا معرفية وهجية، تتجلى في صورة الثنائيات تتفاعل أطرافها بطرق مختلفة في آيات القراتن.

\section{منهج البحث:}

اعتمات في البحث على المنهج الوصفي الاستقرائي تارة والتحليل البنيوي تارة أخرى بتتبع ثنائيات سورة الرحمن في القرآن وتصنيفها وترتيبها.

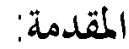

البحث يبحث في مبدأ "الثنائيات" وهي حقيقة قد اتفق العلماء والفلاسفة وأهل الدين حوها، وبتملت في ظاهرة الكون، فحقيقة الزوجية حقيقة ثابنه للعيان، ومظهر من مظاهر الإعجاز في الخلق. وكل 
الأزواج والثنائيات متداخلها بعضها مع البعض في العلاقات، حيث تتخذ أشكالا مختلفة: العبودية الاستسلام والخضوع لله، والتسخير والإنعام "ثنائية الطبيعة والإنسان"، التتابع والتوالي والتوازن "ثنائية الليل والنهار، السماء والأرض، القمر والشمس"، ثنائية الثصادم والتكامل "لموجب مع السالب" التعاون والتآزر والتكافل "الفقير الغني، القوي الضعيف، الكبير والصغير". كثير من الثنائيات تعلد أعملة الساسية بالثقافة الإسلامية منها "الدنيا والآخرة، التوحيد والشرك؛ التقوى والفجور، الجنة والنار، النور والظلام، الإصلاح والإقساد". هناك ثنائيات ها صلة بالآفاق والكون "السماء والأرض، الصيف والشتاء، الظلام والنور، النهار والليل". مصطلح "الثنائيات" نجد يغيب في كتب الاصطلاحات سوى النرات القليلة منه. وحسب ما قال الخليل: "كالام العرب مبني على أربعة أصناف: على الثنائي والثلاثي والرباعي والخماسي، فالثنائي مبني على حرفين" نهو: قد، لو، بل، هل. ويمكنا أن نقول الثنائي كل شيء انطوى على اثنين. الثنائية جزء موري وأساسي في الكون، حيث لا يسع للمتأمل إلا أن يقر به. تنفرد سورة الرحمن عن باقي سور القرآن الكريم بافتتاحها باسم الله و اسماء الله الخسنى "الرحمن"، وأن خطابها موجه للخلق "الجن والإنس" ، "سنفرغ لكم أيها الثقلان"1 ، و "يا معشر الجن والإنس" "2 وتكرار الآية "فبأي آلاء ربكماء تكذبان" لإحدى وثلاثين مرة. وميزةا بأها تمتاز بوفرة الثنائيات بشكل

$$
\begin{aligned}
& \text { جلي بارز، من الشلك والمضمون. } \\
& \text { ثنائيات القرآن عموما }
\end{aligned}
$$

نظام الثنائية هي مظاهر الكون القرآن مصدر للمعرفة الكونية المطلقة بوصفه المعادل الموضوعي للكون، القرآن قد قصل بأنواع الثنائيات، ووضح مظاهرها وبتلياتها، وهي مرتبطة بقضايا موضوعات ومركزية،

${ }^{1}$ Alrahman 55: 31

${ }^{2}$ Al Rahman 55: 33 
القرآن يعالجها بقصدية ومنهجية التي تستجيب لحاجات الإنسان المعرفية والغيبية والواقعية، التي تنسجم وسنن الحياة، وأكثر الثنائيات تعل أعمدة أساسية للثقافة الإسلامية، القرآن يتمحور حول روية الكلية التي تمد الإنسان بآليات منهجية ومعرفية لأجل فهم قضايا وإشكاليات التي تكون مرتبطة بالوجود، وهي إشكاليات مركزية مسيرة في الحياة الإنسانية. وكثير من الثنائيات تتفاعل أطرافها بطرق مختلفة تتخذ

$$
\text { عموماً منهجين هما الرئيسين فيها وهما: تمنهج التكامل و منهج التقابل. }
$$

ثنائية الخالق والمخلوق: ثنائية الوجودية، إله خالق خلق الكون3، وهي تثبت عبر الآية الأولى القرآنية قوله تعالى: "أقرأ باسم ربك الذي خلق" "4، "حيث انحاز الرب لجهة والمخلوقات لجهة أخرى" 5. تُنائية الإنسان والطبيعة: الإنسان والطبيعة كلاهما مخلوقان، لكن الإنسان تفرد بعناية إلهية تفرد بها عن المخلوقات، فكان المخلوق المكرم الوحيد الذي هبه الله العقل، والطبيعة فضاء للاستخلاف الحاضنة للإنسان، فعلاقة الثنائية هي علاقة نفعية، لا شك في أن الخط المنطلق هو الاحتياج، حيث لا غني للإنسان عنها، فهو يرعاه ويخفظها، ويستفيد منها ويتنعم بخيراتجا.فالعلاقة بينهما الحاجة والاستفادة. ثنائية الدينا والآخرة: الإنسان له في حياتة مرحلتين إحدهما دنيوية، والثانية أخروية، وكلا الدارين لما صفاتما، الدنيا ذات عمر قصير ولعب وزينة ودار الغرور، والإغواء لترف الدنيا، او لكسب الحسنات وعمل الصاخ، الآخرة حياة حقيقة، دار القرار متفاوتة في الدرجات ومنازل الإنسان على حسب الأعمال، حيث الجزاء والحساب وكل يكساب حسب عمله واستحقاقة"'6.

ثنائية الذكر والأنثى: وهي من أبرز الثنائيات حيث توضح حقيقة الزوجية بين الصنفين، وهي في كل

3 Eabd Alwahaab Almasiri, Rihlati Alfikriat Fi Albudhur Waljudhur Walthamar Sirat Ghayr Dhatiat Ghayr Mawdueiatin, P184, Cairo, Dar Alshiruq, Ed1, 2006A.D

${ }_{5}^{4}$ Al-Alaq 96:1

5 Eabd Almajid Alnajaar, Khilafat Al'ansan Bayn Alwahy Waleaqla, P41, Firjinya Almaehad Alealamii Lilfikr Al'iislami Ed2, 1413H

6 'Iilyas Bilka, Alghayb Waleaqla: Dirasat Fi Hudud Almaerifat Albashariati, Page 125,Almaehad Alealamii Lilfikr Al'iislamii, ed1, 1429H. 
الأصناف المخلوقة قال تعالى: "فجعل منه الزوجين النكر والأنثى"7. العلاقة بينهما السكن والرحمة والمودة.

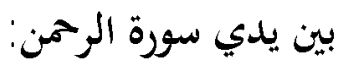

سبب التسمية: سميت السورة باسم الرحمن على اسم من أسماء سبحانه وتعالى وهو لفظ "الرحم" التي تعني الرممة التي وصف الله بما نفسه، وكثير من العلماء قالوا بأنه هناك سبب آخر للتسمية وهو لأنما تتحدث عن رحمة الله الواسعة والشاهلة. وبها عدد من الفضائل حيث استمع ها الجن، وأها تشفع لصاحبها يوم القيامة تكون سبا في تثفيف الحساب والكرب. وأيضا لها الفضل بأهما تشعر بالسكينة والطمأنينة، وتكافي قارئها بدخول الجنة. وها مقاصد ودلالات يصعب حصرها من أبرزها شثوها على بيان رحمة الله،

ترتيب السورة وعدد آياتما :الحقل الدلالي يعرف بأنه المجموعة الجزئية من المعجم حيث تشترك بمفوم معين معهاه. إذن الحقل الدلالي مزاوجة بين حقل معجمي وبجموعة الوحدات المعجمية التي يجمعها التي تضع للتحليل اللساتي والحقل المفهومي. الحقول الدلالية تنطلق فكرةا من فرضية بأن البنية الدلالية مؤلفة من بنى موحدة.

\section{فضل السورة على السور الأخرى:}

عن علي رضي الله قال سمعت رسول الله يقول: "لكل شيء عروس وعروس القرآن الرحمن". وعن الرسول "ص" قال: "من قرأ سورة الرممن أدى شكر ما أنعم الله عليه".

${ }^{7}$ AL-Qiyamah 75:39

${ }^{8}$ V oir, Georges M ounin: Clefs pour la semantique, pp 59, 60

9 'Iilyas Bilka, Alghayb Waleaqla: Dirasat Fi Hudud Almaerifat Albashariati, Almaehad Alealamii Lilfikr Al'iislamii, vol6, P.2494. 


$$
\text { السورة الكريمة تناولت عدة ماور كتالي: }
$$

المحور الأول: الإثبات: قد ركز هذا المحور على ثلاثة اجزاء حيث المشهد الأول يصف القدرة

الألمية، خلق الكون السموات والأرض، المشهد الثاني يتناول الالنفات للنات الإنسانية ومكوناتها، المشهد الثالث نجلده يناقشة القدرة والسيطرة على الماءو، جميع المشاهدة تخدم الإنسان، فنجد التقابل والتكرار في السورة يؤدي وظيفة الاسترشاد والاستيعاب.

نجد ان السورة توجه الإنسان لمفتاح الوجود، وهي منهج السماء والأرض حيث ان القرآن يقدم التعليم

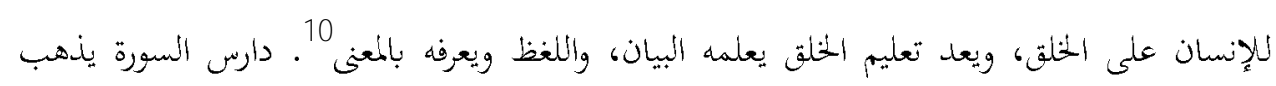
لتعليم البيان على خلق الإنسان مع الراي القائل "فذكر ما نشأ عن صفة الرحمة، ... وملا علد نعمه تعالى بدأ من الأعلى وهو التعليم حيث أنه عماد الدين" ل11. اتخذت من التقابل أسلوب لأجل توصيل الفكرة، "الشمس والقمر بكسبان"، ومشهد مزدوج "النجم والشجر يسجدان". أفرد السماء في "السماء رفعها" والأرض أفردها "والأرض وضعها للأنام". يناقش النص القرآني مظهر هذه القدرة الإلهية المتنجلية في الخلق والإنشاء، من خلال استخدام التقابل الذي تكتنز به الآيات والذي يجيء لقياس المسافة بين المتقابلين والمتضادين، والثقابل يظهر على مستوى اللفظ ويتجلى أكثر على مستوى الباطن، أي ما تثيره هذه الألفاظ المتقابلة، فالإنسان يقابل الجان، الإنسان مسوس، والجان غير محسوس، الإنسان عالم جلي، والجن عالم خفي، مكون الجان من النار، ومكون الإنسان طين لزج، هذا الثقابل يفضي إلى التناسب، والتناسب صورة التكامل الجمالي

${ }^{10}$ Sayid Qutb, Fi Zilal Alqurani, P.672 Biruti-Lubnan, Dar 'Iihya' Altarathi, vol23, 1971.A.D

${ }^{11}$ Uthir Aldiyn 'Abu Hayaan Muhamad Yusuf Al'andalsi, Albahr Almuhit Fi Altafsiri, P54 


\section{ثنائيات القرآن دراسة سورة الرحمن دلالية بلاغية}

الذي يمكنه حمل الأبعاد الشعورية والفكرية الكامنة في النص، والمفهوم الطيني أصل مادة الإنسان،

$$
\text { وأساس تكوينه. }
$$

وانطلاقاً من أن اللغة بمموعة علاقات وظيفتها تمكين المخاطب من أخذ صورة ذهنية عن أشياء لا

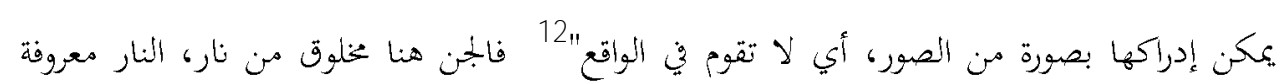
بوصف ها مادة والمخلوق غير مدرك بوصفه جسماً.

المحور الثاني: مقاطع العذاب: هذا المحور، وفق النص القرآني باستعراض مظاهر القدرة الإلهية ولكن بالتأكيد، لأغراض مختلفة هنا، إذ اتسم الإنسان في هذا المحور بوصف خاص، والحديث عنه الآن

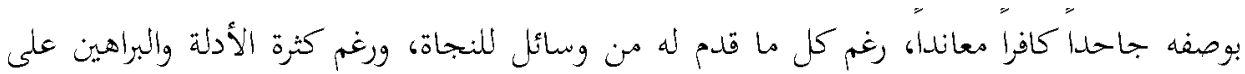
وحدانية الله. ولذلك تسود في هذا المحور دلالات لمفردة القدرة الإلهية من مثل: القوة والتحدي والمحاصرة والإجبار والتهكم الاستهزاء والوعيد والتحقير، وتخيم في ثاية النص القرآئ في هذا المقطع جهنم، بوصفها حقيقة ثابتة لنهاية مؤمة. يبدأ النص القرآي بالإبادة ثم يستعرض مشاهد مرعبة خيفة، يساق فيها المجرم وصولاً إلى جهنم، وفي خضم هذا يمر الزمن على المجرم بطيئا ليتجرع العذاب مرات مضاعفة. فالآية التي يفتتح بها هذا المقطع "كل من عليها فان" إلى قوله "يطوفون بينها وبين حميم آن" هي أيضا" من نعم الله ويذهب الدارس مع الرأي القائل "لولا أن يقال إها ليست نعماً فكيف قال عقب كل آية منها "فبأي آلاء ربكما تكذبان"؟ والجواب أن ما وصف من هول "يوم القيامة، وعقاب البمرمين فيه زجر عن المعاصي، وترغيب في الطاعات، وهذا من أعظم المنن". وقيل وجه النعمة بفناء الخلق وأن الموت سبب التنقل للدار التي ينال فيها الجزاء والثواب،"أبتلك النعم من بقاء الرب وفناء الكل والحياة

$$
\text { الدائمة والنعيم المقيم أم بغيرها... "13. }
$$
هذا الكون لا يملك القدرة على فنائه إلا الله، فكما كانت هناك بداية فهناك فهاية، حيث يتمركز المُعنى

12 Rashidu, Alhujajiaat Allisaniatu, Ealam Alfikr, vol.34, p214

13 Alqanuwjii, Fath Albayan Wamaqasid Alquran, vol.13, p325 


\section{ثنائيات القرآن دراسة سورة الرحمن دلالية بلاغية}

النذي يريد الله تأكيده للإنسان في "فبأي آلاء ربكما تكذبان" تهويلاً وتخويفا، استئنف معكوس لعناصر البداية/ يكسبه هذه الهيئة المتجددة. بعد هذه اللوحة الجميلة التي وصفتها الآيات في ذروة

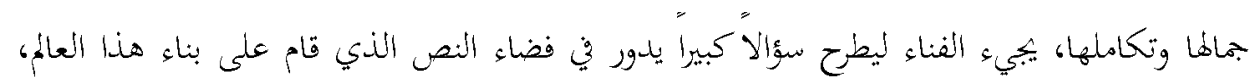
وهو بحد ذاته سؤال يكيل على الموضوع ذاته -قدرة الله-، وتتجلى "فبأي آلاء ربكما تكذبان" على أهنا وعاء يكتوي ذات الغرض، تعظيم قدرة الله، وتذكير الإنسان بها وبعد من أبعاد الحركة السريعة والآنية الفعل القدرة ذاته، "عملية لا ينفصل فيهما المسموع عن المفهوم والمرئي" "14. الخور الثالث: مقطع الثواب: الجزء الخاص بالمكافأة بالجنة أو النار وهذه الجنة وعد بها سبحانه وتعالى للمؤمنين، والتي جاءت لأغراض على سبيل التكثير والدعاء والتمني والاسئناس والترهيب والترغيب.

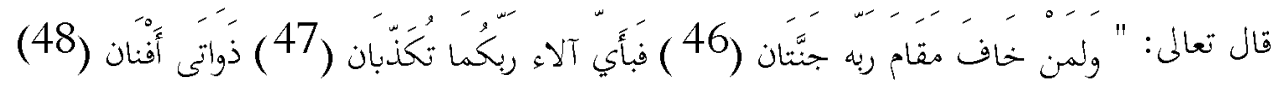

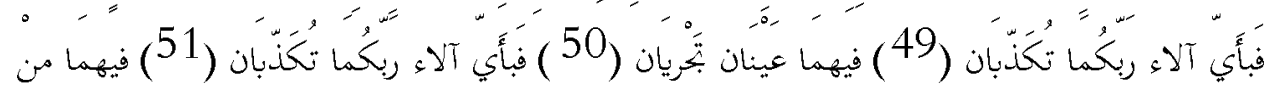

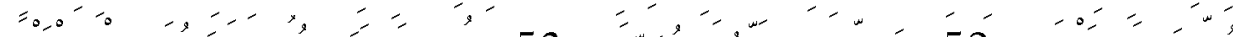

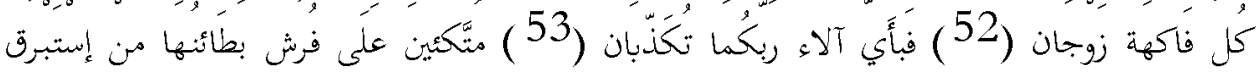

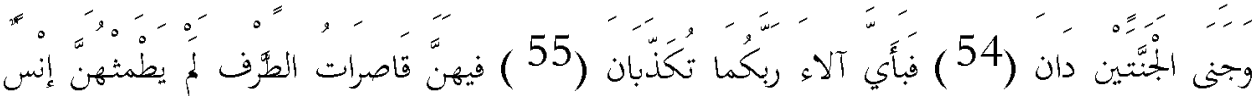

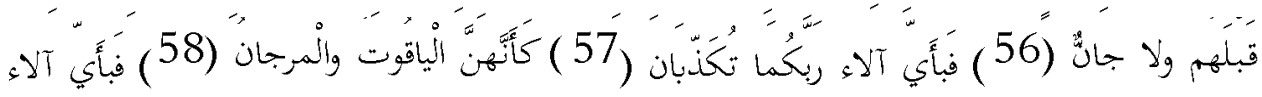

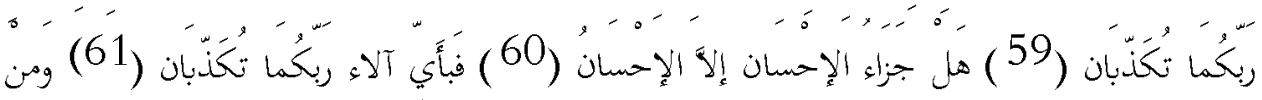

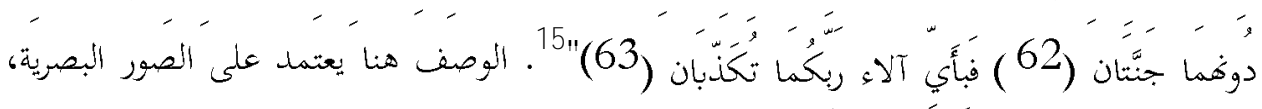
والإحساس والإدراك الحسي، وهو الذي تشير إليه الآيات والصور البصرية تكمن "في الدلالية الوجدانية والمعنى الإيحائي، وليس فقط فيما تبوح به من المعنى الحسي أو الذهني المباشر"16. وقيمة الصور البصرية

${ }^{14}$ Jabir Easfura, Mafhum Alshiera, Alqahirata, P,214, Dar Altibaeat Lilthaqafati $2^{\text {nd }}$ Ed. 1978A.D,

${ }^{15}$ Alrahman 55: 63-64

${ }^{16}$ Bushraa Salih, "Alsuwrat Alshieriat Fi Alnaqd Alearabii Alhadithi, P.6, Almarkaz Alearabia", Bayrut, Ed1, 1994A.D 


\section{ثنائيات القرآن دراسة سورة الرحمن دلالية بلاغية}

كمن "في الدلالية الوجدانية والمعنى الإيمائي، وليس فقط فيما تبوح به من المعنى الحسي أو الذهني

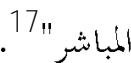
وفي المقطع الأخير خصص الله جزء للمؤمنين في الجنة، وقد لفت الآية بالأسلوب اللغوي الوثيق الارتباط بالمعنى العام، ذات الأبعاد الدلالية وثراء الموجودات فيالجنة من النعيم، وتعمل الاية المكررة على تتبيت المعنى ودعمه، والتحفيز على متلقي النص القرآني، والعيش الإمكاني والمتخيل في ظلال النعم الموصوفة حيث تساعد على إنتاج إنسان ذي نسق خلقي ديني. دلالة الجمل في هذا المقطع تسمح للمتلقي باحتمال جلب أي متعة، حتى إن القارئ يظل مرهوناً باستراتيجيات النص التي تخرجه من

\section{التثنية في العربيةت}

صيغة التثية مستحدثة بالعربية امتازت بما العربية دون عن اللغات السامية الأخرى، "النثية بالعربية مؤشر يدل على دقة وأمعان العربية في التعبير عن الأشياء بكقائقها، لأهما فصلت بين المفرد والجمع بالمثنى، لأنه ليس مفرد لأنه ليس واحلد، ولا بالجمع لأنه ليس بالكثير. تكرار للواحد وتضعيف للجمع، حيث المفرد يدل على واحلد والجمع يدل على الكثرة بينما المثنى دليل على الاثنين او الاثنتين 19. الثنيا بالضم: الاسم من الاستثناء، جاؤا مثنى- أي أثنين، وثنيت الشيء ثنيا: عطفته. صرفته عن حاجته 20. الثنائية هي: "القول بزوجية المبادئ المففرة للكون كثنائية الأضداد وتعاقبهما.. ثنائية الواحد وغير المتناهي عند الفيثاغورسين، عالم المحسوسات عند أفلاطون.21.

${ }^{17}$ Eabd Al'iilah Alsaayghi, Alsuwrat Alsameiat Meyaraan Nqdyaan, P409

${ }_{18}$ Muhamad Kharmash, Fiel Alqira'at Wa'iishkaliat Altalqi, Ealamat Almaghribiati, 1998A.D, P53

${ }^{19}$ Ibn Fares 1987, P.307

20 'Iismaeil Bin Hamaad Aljawhari, "Alsihah Taj Allughat Wasihah Alearabiati",P.3/757, Dar Aleilm Lilmalayini, Bayrut, Lebanon, $4^{\text {th }}$ Ed. $1407 \mathrm{H}$.

${ }^{21}$ Alduktur Jamil Silbia, Almuejam Alfalsafi, P.1/379, Dar Alkitaab Lebanese, Bayrut. 


\section{ثنائيات القرآن دراسة سورة الرحمن دلالية بلاغية}

الثنائيات هي جمع ثناء، وهو الحبل المثنى، ياتي من الثني لمصلر الفعل ثنى، الثنية مصدر للفعل ثني ردانية

$$
\text { جعل الشي الواحد اثنين.22. }
$$

أما في الأدب واللغة نتلمس ملامح الثنائية عند اللغويين القدماء بظاهرة التقابل، حيث في النمط الثنائي القديم اتسم بالتوافق بينه وبين المجال الذي يرد فيه، ح بيث يأخذ شكالاّتحوليا لينتقل من حالة لأخرى.

\section{الثنائيات في الآيات القرآنية:}

مصطلح 》الثنائيات) ومعانيه في كتب الاصطلاحات والتعريفات العربية سوى بعض الشذرات القليلة التي لا تفي بمقصودنا في هذا الموضوع، ومن ذلك القليل ما قال الخليل: كلام العرب مبني على أربعة أصناف: على"الثنائي والثلاثي والرباعي "والخماسي،"قالثنائي على حرفين"، نخو: "قد، لم، هل، لو، بل، ونغوه من الأدوات والزجر "23.

لا شاكُّ أن الثنائية جزء أساسي ومحوري في هذا الكون النذي خلقه الله عز وجل الفرد الصمد، ولا يسع

المتأمل فيه إلا أن يقر بحقيقة الزوجية في بناء الكون، مما يدلُ على وجود أسرار كامنة وراء بتحليها في

المخلوقات برهتها (النكر والأننى، النيل والنهار، النور والظلام، الروح والمادة، الحياة والموت، الدنيا

والآخرة...). هذه الثنائيات ـ التي خلقها الله تعالى، وجعل لنا منها آيات للاعتبار وسننا للتعمير والبناء.

هي المحدد الأساسي لخركتنا في التاريخ، وسيرنا الحضاري والاستخلافي بغية تغليب أو تحصيل أطرافها

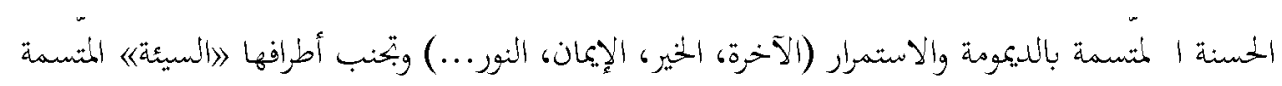

بالمحدودية والانقطاع (الدنيا، الشر، الكفر، الظلام..). وأثناء ذلك السير يجمع الإنسان في نفسه

وتتجسد في حياته عدد من الثنائيات، وأساليب الكثرة والتنوع؛ لكي تتبلور فيه حقيقة الوحدة فيما

22 'Iibin Manzur 'Abu Alfadl Jamal Aldiyn Muhamad Bin Mukram,P115, Lisan Alearabi, Dar Sadir, Ed3, 1414H

23 'Abu Ebd Alrhmn Alkhalil Bin 'Ahmad Alfarahidi. (written: 175H) "Alein.." Tahqiqu: Mahdii Almakhzumi, 'Iibrahim Alsaamaraayiy, $1^{\text {st }}$ Ed, Baghdad 1980 1985, P1/48 
بعل، " فلكي يصل إلى ذروة الأمن والاطمئنان عليه أن يعيش أشدُّ أنواع القلق والاضطراب ! والفرد لا يتذوق اليسر بكامله إلا حين يمتص العسر بكامله. ولا ينفتح على جميع الكون إلا بممارسة التقيد

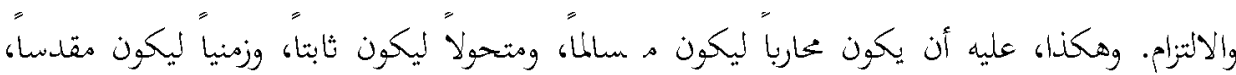

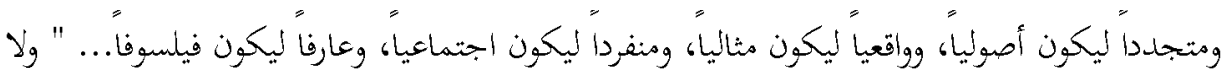
بلَّ أن يكتشد فيه كل ثنائيات المكون؛ لتتوحد شخصيته،"وتزول عنه كل ثنائيات الكون ! غريب سر هذا الإنسان ! كيف تتجسد فيه كل أساليب الكثرة؛"لكي تتبلور فيه كل حقيقة الوحدة؛24. وهذا التنوع في التصوير والتعبير يبعل انسجام تام لحقيقة واحدة، ووفكرة معينة تعبر عن أساليب شتى، تجعل القرآن يكون نسقاً واحدا بالموصوعات حيث ياتي الثفسير بمواضع بيان الحال، عندما يصف الكفار وقلوبمم الميثة والذلة والصغار والقساوة والانصراف والضيق مع المرض.. ونجد المؤمن يصف بالحياة والعزة، والرقة والأمن... بمواضع أخرى نجد العاقبة والفوز حيث يستحق الجنة والنعيم والسعادة والتيسير والثوفيق وهو زمر للثنائيات بينها أواصر مشتركة موضوعيا، حيث يوضح القرآن ويصدق بعضه

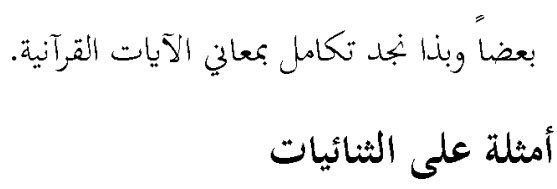
الثنائية الأولى:

الثنائية الكونية: آيات الليل والنهار: قال تعالى: "إن في خلق السموات والأرض واختلاف اليل والنهار والفلك التي تجرى في البحر بما ينفع الناس وما أنزل الله من السماء من ماء فأحيا به الأرض بعد موقا وبث فيها من كل دآبة وتصريف الريح والسحاب المسخر بين السماء والأرض لأيات لقوم يعقلون"25.

${ }^{24}$ Muhamad Khaqani, "'Amr Bayn 'Amrayni, Thunayiyaat Al'iinsan Walkawn Bimantiq Altaawil Waltafsiri" Dar Alhadi, Bayrut, Ed.1, 1420H P-8

${ }^{25}$ Al Baqarah 1:164 
سورة آل عمران قال تعلى: "إن في خلق السموات والأرض واختلاف اليل والنهار لآيت لأولى الألباب"26. وقال تعالى: "إن في اختلاف الليل والنهار وما حلق الله في السموات والأرض لآيات لقوم يتقون"27. نجد افتتاح الآية بحرف التوكيد "إن" لهاية المخاطبين وللمنكرين في آيات الوحدانية لعدم 28 جريهم على موجب العلم نبهت الآيات لعظيم خلق الله في خلق الكون، ومنها خلق الليل والنهار، وهي عبارة عن مجموعة الحوادث التي تتجدد في العالم وقت طلوع القمر والشمس وغروبهما، وسير الرياح والسفن والنجوم وكل تلنك الأحداث الكونية.29. نجد الثنائية "السماء والأرض" وردت أربع مرات في السورة قال تعالى : "والسماء رفعها ووضع الميزان"30، السماء تفيد الارتقاء والسمو وجمعها سموات، وكذلك الأرض التي تشير للكوكب الذي يعيش عليه الأنسان 31 ونجال لفظ الأرض يتكرر في السورة ثلاث مرات مواقع مختلفة. وهي ثنائية التضاد السماء ضد الأرض وهو تضاد اتجاهي الشمس والقمر: الشمس الكوكب الملتهب الني يبعث الحرارة والضوء للأرض وسكانها والقمر كوكب يستمد نوره من الشه س ويلدور حول الأرض ويضيء الليل. ونجد لفظ الشمس والقمر معاً قد وردا مرة في السورة في قوله تعالى: "الشمس والقمر بكسبان" "32. كلاهما ثنائية التضاد ابتحاهي.

\footnotetext{
${ }^{26}$ AlImran 3:190

${ }^{27}$ Youns 10:6

${ }^{28}$ Muhamad Altaahir Bayn Eashur, Altahrir Waltanwiru, P11/97, Aldaar Altuwnusiat Lilnashri, Tunis $1404 \mathrm{H}$.

${ }^{29}$ Eizu Aldiyn Muhamad Bin 'Iibrahim Alyamani, 'Iithbat Alhaqi Ealaa Alkhalq Fi Radi Alkhilafat 'Iilaa Almadhhab Alhaqa, P51 Dar Alkutab, Beirut, Lebanon.

${ }^{30}$ Alrahman 55: 7

31 Muhamad 'Tismaeil, Muejam Al'alfaz Wal'aelam Alquraniati, P36, Dar Alkutub Aleilmiati Beirut Ed1.

${ }^{32}$ AlRahman 55:5
} 
لقد ورد لفظ خلق: 3 مرات في ثلاث آيات نحو قوله تعالى: "خلق الإنسان" الآية تدل على معنى الأبداع عن تقدير والحكمة.

النواصي والأقدام: هي أعضاء الأنسان الناصية هي مقدمة الرأس وورد مرة واحلدة، الأقدام يقصد به

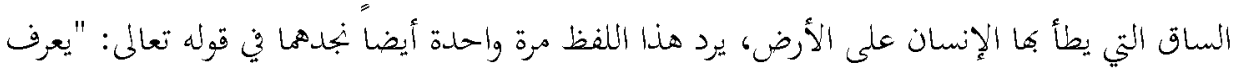
المجرمون بسيماهم فيؤخذ بالنواصي والأقدام" ثنائية الكون: المشرقين والمغربين: المشرقين تلك المنطقة التي بين الشرق والغرب وتصيبها الشمس لدى طلوعها وغروبما يعني بالمشرق الشمس صيفا وفي الشتاء، المغربين المكان النذي ينتهي إليها الثمس عند الغروب والمسافة بين المغرب الأقصى والمغرب الأدنى حوالي مائة وثمانون مغرباّل3. وقد ورد لفظ المشرقين مرة في قوله تعالى: "رب المشرقين ورب المغربين" 35. تضاد ابتحاهي ثنائيسة النهي والأمر: النهي: لا تخسروا: الخسارة ضـد الربح جاءت كلمة "لاتخسروا" مـرة واحدة في قوله تعالى: "وأقيموا الوزن بالقسط ولاتخسروا الميزان" "36. لفظ "لاتنتصران" يفيد الامتناع من الظلم والنصرة على الخحم وقد وردت لفظ "لاتنتصران" هـرة في السورة في قوله تعالى: "يرسل عليكما شواظ من نار ونحاس فلا تنتصران"

\footnotetext{
${ }^{33}$ AlRahman 55:41

${ }^{34}$ Jamal Aldiyn Abn Manzur Al'ansari, Lisan Alearabi, P 747, Dar Sadir, Beirut, vol1, $1414 \mathrm{H}$

${ }^{35}$ AlRahman 55:17

${ }^{36}$ AlRahman 55:9

${ }^{37}$ AlRahman 55:5
} 
الأمر: أقيموا: جاءت من أقيم يقيم الحق، شرعاً: يعمل بأحكام، وقد ورد لفظ "أقيموا" مرة واحلدة في

$$
\text { قوله تعالى: "وأقيموا الوزن بالقسط ولا ثخسروا الميزان"38. }
$$

ثنائية التضاد: نجد من دراسة الثنائيات الدلالية لسورة الرحمن في التالي: جهنم= نار، الميزان= القسط،

$$
\text { لا تنفذون = لا تنتصران، نضاختان=تجريان. }
$$

العلاقة بين الالفاظ هي كما يلي: جهنم = نار: لأن جهنم هي من اسماء النار والنار تدل على الجهنم التي يعذب الله بكا العباد المجرمين.

الميزان = القسط وهي للدلالة على العدل والحكم العادل كما في قوله تعالى: "وأقيموا الوزن بالقسط ولا

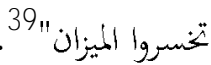

نضاختان=تجريان، النضخ هو الماء الذي يشتد فوارنه من الينبوع ونضخ الشيء أي فار بشدة وبلل، قال تعالى: "فيهما عينان نضاختان" 40 بتحريان: تسعيان لسقي الأشجار والأغصان لتعطي الثمار المختلفة.

ثنائية البداية والنهاية: لسورة الرحمن ركنان في الثنائية هما البداية والنهاية، وهو: 1. البداية بأسم الرحمن، الانتهاء بتبريكة وتفسيره "تبارك اسم ربك ذي الجـلال والإكرام" "4أل لأن

$$
\text { 2. كلمة الرحمن متضمة معنيين: الاول ذي الجلال الثاني ذي الإكرام. }
$$

\footnotetext{
${ }^{38}$ AlRahman 55:9

39 AlRahman 55:9

${ }^{40}$ AlRahman 55:22

${ }^{41}$ AlRahman 55:78
} 


$$
\begin{aligned}
& \text { 3. ختم نعم الدنيا بالفناء، ختم نعم الآخر "تبارك اسم ربك ذي الجلال والإكرام" حيث تبارك } \\
& \text { هي صفة على وزن تفاعل. لاتكون سوى لله سبحانه وتعالى. هي تاتي بمعنى تقدس الله وتنزه } \\
& \text { وتعالى وتعاظم بـ ختمت نعم الآخرى لأمرين: } \\
& \text { 1. متناسبة لمضمون السورة بجملتها لما تحتوية من عظم خلق الله } \\
& \text { 2. تتناسب مع معنى الخلود من ناحية النعيم لأهل الجنة، قال رسول الله (ص) أن أهل } \\
& 43, \\
& \text { الجنة "يلهمون التسبيح والتحميد كما يلهمون النفس" } \\
& \text { 3. بدأ الحياة بقوله: "سنفغ لكم أيها الثقلان"، وأعلن عن غاية الدنيا بقوله "يبقى } \\
& \text { ووجه ربك ذو الجلال والإكرام". } \\
& \text { 4. الحميث عن الجنة يستهلها بـ"ومن خاف مقام ربه جنتان" والحميث عن النار: } \\
& \text { "هذه جهنم التي يكذب بها المجرمون". } \\
& \text { ثنائية الحياة والآخرة: نرى سورة الرحمن منقسمة لقسمين رئيسين: }
\end{aligned}
$$

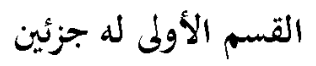

$$
\begin{aligned}
& \text { الأول: قسم الحياة الدنيا وهي نرآه في الآية الاولى للآية السادسة والثلاثين } \\
& \text { الثانية: من الآية السابعة والثلاثني حتى هاية السورة اي الآية الأخيرة. }
\end{aligned}
$$

42 Ibn Manzur, Lisan Al-Arab, Article Barak, vol10, p.396

${ }^{43}$ Sahih Al-Muslim, Investigated By Nazar Bin Muhammad Al-Farabi Abu Qutaiba, Dar Taiba, 1, $1427 \mathrm{AH}$, Chapter On The Characteristics Of Paradise And Its Inhabitants, And Their Glorification In It Tomorrow And Evening, Hadith No. 2835, P. 1301 


$$
\text { القسم الثاني ثناية المحاور: منقسم لقسمين }
$$

الأول: السؤال والجواب، هذه السورة هي جواب ورد سبحانه وتعللى لسؤال المشركين

والمنكرين وهذه الثنائية تتألف من ضمير الغائب يرجع لجل جلال سبحانه وتعلى، يستخدم فيه ضمير

$$
\text { المتكلم، هي رسالة سبحانة على لسان نبية. وتعظيم وإجلال من سبحانه لمخاطبتهم. }
$$

الثاني: ثنائية المخاطب: ثنائية المخاطبة أخرجت الخطاب من حيز الخصوص لحيز العموم لأن

$$
\text { ليس الخطاب هنا موجه للمشركين بل نراه يخاطب وموجه للعموم لكل من الجن والإنس. }
$$

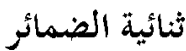

\section{ضمائر المثنى لها أربعة أنواع}

\section{1}

$$
\text { أ- يسجدان تعود للنجم والشجر "والنجم والشجر يسجدان" }
$$

ب-تكذبان: "فبأي آلاء ربكما تكذبان" تعود للجن والإنس"، تشكل ثنائية ضمير

الجمع، هي محمولة على اللفظ في عطف المي الجنس الجمعي للجن والأنس،

نرى ضمير الجمع يكمل على المعنى: "يا هعشر الجن والإنس إن استطعتم أن تنفذوا

$$
\text { من أقطار السماوات والأرض فانفذوا لا تنفذون إلا بسلطان"ب44. }
$$

ج- يلتقيان: تعوئد للبحرين، حذف الظرف المضاف مرج: "مرج البحرين يلتقيان"45.

د- تنتصران: تعود للجن والإنس: "يرسل عليكما شواظ من نار ونحاس فلا تنتصران".

\footnotetext{
${ }^{44}$ AlRahman 55:33

${ }^{45}$ AlRahman 55:19
} 


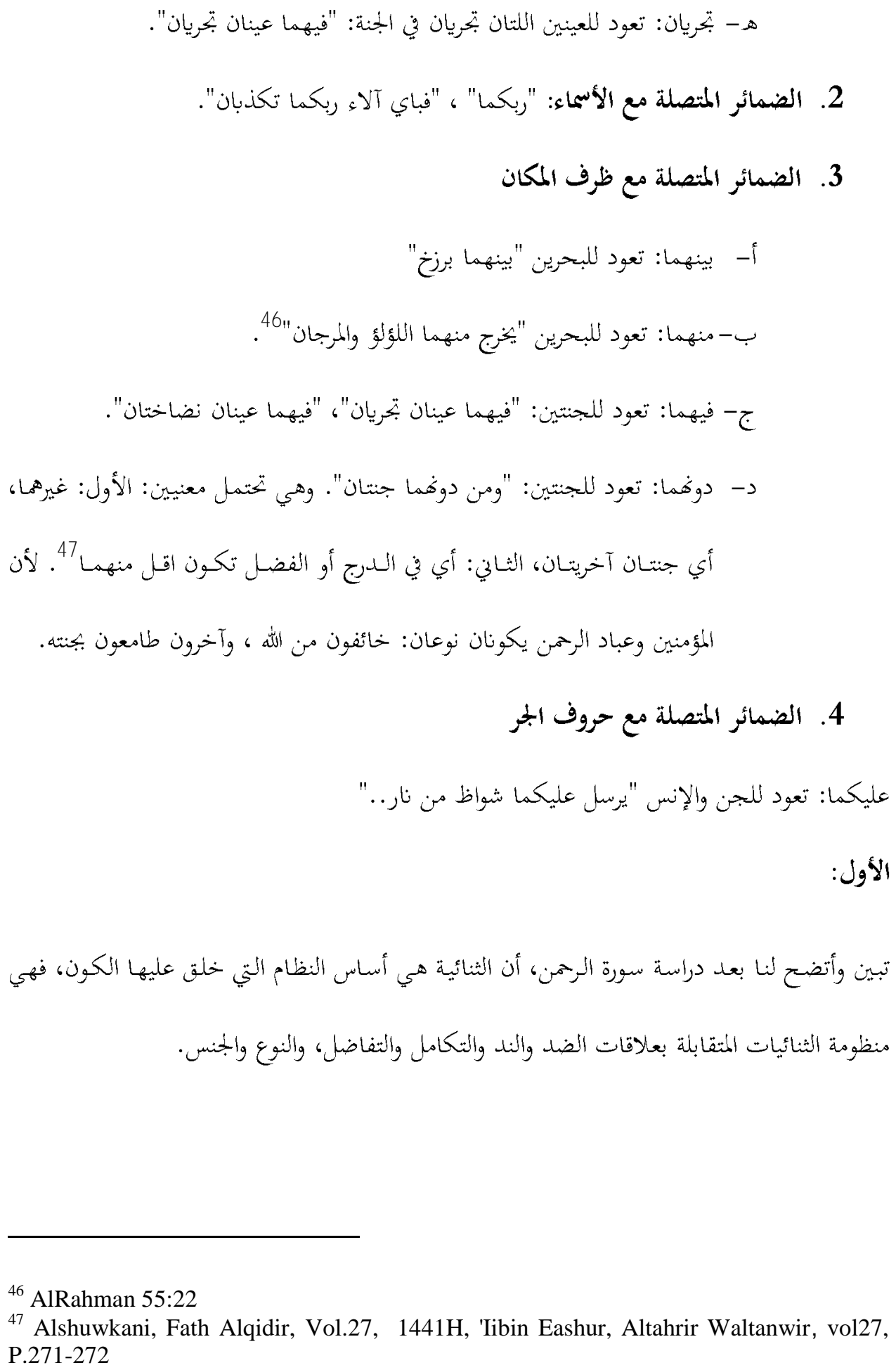

${ }^{46}$ AlRahman 55:22

47 Alshuwkani, Fath Alqidir, Vol.27, 1441H, 'Iibin Eashur, Altahrir Waltanwir, vol27, P.271-272 
The Scholar Islamic Academic Research Journal

Vol. 7, No. 2 || July-December 2021||P.29-46

https://doi.org/10.29370/siarj/ issue13arabic2

واتضح لنا أن الثنائيات مشيات "المشرقين، المغربين، البحرين"، الثنائيات موجود بالمفردات بنية "الثقلان"

$$
\text { وقي المضمون "الميزان". }
$$

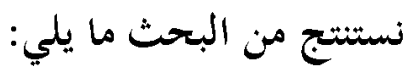

الثنائيات والجانب الدلالي له قيمة كبيرة في فهم النصوص القرآنية، وهي صفة تحتويها فقط النصوص

القرآنية.أهم ما ميز سورة الرحمن أفا غنية بالثنائيات الدلالية وخاصة الدالة على الطبيعة وعلى عظمة

الخالق وقدرته. وجلنا تفاوت في الثنائيات الدلالية من حيث الحجم نظرا لأهميتها ومكانتها في السورة

توصلت الدراسة للتوصية التالية هناك ضرورة للعناية فهم الحقول الدلالية والفاظ القرآنية الخاصة بسياق

$$
\text { دلالي، لكي يتم الكشف عن الثراء اللفظي القرآي. }
$$

